patients: 72 vs. $47 \%$ for Degree of Relief of IBS Symptoms, 70 vs. $47 \%$ for Degree of Relief of Abdominal Pain, and 59\% vs $33 \%$ for SBM frequency (all comparisons: $\mathrm{p}<0.0001$ ). For all parameters, most linaclotide-treated patients $(\geq 70 \%)$ who had response at Week 4 were improved at Week 12. For linaclotidetreated patients whose symptoms were unchanged at Week 4 for Degree of Relief of IBS Symptoms and Degree of Relief of Abdominal Pain, 36 and 39\% were improved at Week 12, vs. 19 and $21 \%$ of the placebo group, respectively $(\mathrm{p}<0.05$ ). For SBM frequency, $30 \%$ of linaclotide-treated patients vs. $17 \%$ of placebo-treated patients without response at Week 4 were improved (SBMs $\geq 2)$ at Week $12(\mathrm{p}<0.05)$.

Conclusion Patients whose IBS symptoms improved after 4 weeks with linaclotide were likely to maintain improvement. At least $30 \%$ of linaclotide patients who were unchanged at Week 4 experienced symptom improvement by Week 12 . The significant differences between linaclotide and placebo in the percentage of patients improved at Week 12 who were unchanged at Week 4 indicates that in some patients $\geq 1$ month of linaclotide therapy may be required for improvement. Hence, an initial course of linaclotide therapy in patients with IBS-C shou.ld be $>4$ weeks.

Study funded by Forest Laboratories, Inc., and Ironwood Pharmaceuticals, Inc.

Disclosure of Interest W. Chey Consultant for: Ironwood Pharmaceuticals, Forest Research Institute, B. Lavins Shareholder of: Ironwood Pharmaceuticals, Employee of: Ironwood Pharmaceuticals, S. Shiff Shareholder of: Forest Research Institute, Employee of: Forest Research Institute, J. MacDougall Shareholder of: Ironwood Pharmaceuticals, Employee of: Ironwood Pharmaceuticals, C. Kurtz Shareholder of: Ironwood Pharmaceuticals, Employee of: Ironwood Pharmaceuticals, M. Currie Shareholder of: Ironwood Pharmaceuticals, Employee of: Ironwood Pharmaceuticals, J. Johnston Shareholder of: Ironwood Pharmaceuticals, Employee of: Ironwood Pharmaceuticals.

\section{PWE-167 EFFECT OF LINACLOTIDE ON IBS-QOL SEXUAL SUBSCALE SCORES IN PATIENTS WITH IRRITABLE BOWEL SYNDROME WITH CONSTIPATION: RESULTS FROM 2 PHASE 3 TRIALS}

${ }^{1} \mathrm{M}$ Currie, ${ }^{2} \mathrm{~S}$ Shiff, ${ }^{1} \mathrm{X}$ Hao, ${ }^{2} \mathrm{R}$ Carson, ${ }^{1} \mathrm{M}$ Baird, ${ }^{1} \mathrm{f}$ Johnston*. 'Ironwood Pharmaceuticals, Cambridge, MA, USA; ${ }^{2}$ Forest Research Institute, Jersey City, NJ, USA

\subsection{6/gutjnl-2014-307263.427}

Introduction Linaclotide is a minimally absorbed guanylate cyclase-C agonist approved for treatment of IBS with constipation (IBS-C). IBS often results in diminished quality of life (QOL), including decreased sexual desire and activity. This post- hoc analysis aimed to determine if linaclotide treatment improved IBS-QOL sexual subscale scores in IBS-C patients, compared to placebo.

Methods Data from 2 randomised, double-blind Phase 3 linaclotide trials in IBS-C were pooled. The IBS-QOL was administered at baseline and Week 12. The sexual subscale includes items on difficulty with sexual activity and reduced sexual desire, both rated on a 5 -point scale $(1=$ not at all, $2=$ slightly, $3=$ moderately, $4=$ quite a bit, $5=$ extremely/a great deal); the sum of both items is scaled to 0 (worst) to 100 (best). Changes in the scores from baseline to Week 12 were compared for linaclotide- vs placebo-treated patients in the intent-to-treat (ITT) population and the Impaired Sexuality (IS) subgroup (baseline sexual subscale scores $\leq 50$ ).

Results Of 1598 ITT patients with baseline sexual subscale scores, $522(33 \%)$ had a score $\leq 50$ indicating significant impact of IBS on sexual desire and activity (females: 484/1439 [34\%]; males: 38/159 [24\%]). At Week 12, linaclotide significantly improved change-from-baseline sexual subscale scores vs placebo in the ITT population and IS subgroup (Table, $\mathrm{p}<0.001$ for both). Although baseline scores for males were higher (better) than for females, improvement vs placebo for males was similar to females in the ITT population and greater for the IS subgroup. However, the male sample size was too small to establish statistical significance.

Conclusion Linaclotide treatment significantly improves IBS-QOL sexual subscale scores in IBS-C patients compared with placebo, in both the total population and in patients with impaired sexuality at baseline.

Study funded by Forest Laboratories, Inc., and Ironwood Pharmaceuticals, Inc.

Disclosure of Interest M. Currie Shareholder of: Ironwood Pharmaceuticals, Employee of: Ironwood Pharmaceuticals, S. Shiff Shareholder of: Forest Research Institute, Employee of: Forest Research Institute, X. Hao Shareholder of: Ironwood Pharmaceuticals, Employee of: Ironwood Pharmaceuticals, R. Carson Shareholder of: Forest Research Institute, Employee of: Forest Research Institute, M. Baird Shareholder of: Ironwood Pharmaceuticals, Employee of: Ironwood Pharmaceuticals, J. Johnston Shareholder of: Ironwood Pharmaceuticals, Employee of: Ironwood Pharmaceuticals.

\section{PWE-168 IS THERE A RELATIONSHIP BETWEEN IRRITABLE BOWEL SYNDROME SYMPTOMS AND SMALL BOWEL BACTERIAL OVERGROWTH?}

${ }^{1} J$ R Hayman*, 'G Pickering, ${ }^{2} D S$ Sanders. ${ }^{1} G$ Physiology, Northern General Hospital; ${ }^{2}$ Gastroenterology and Liver Unit, Royal Hallamshire Hospital, Sheffield, UK

10.1136/gutjnl-2014-307263.428

\begin{tabular}{lllllllll}
\multicolumn{2}{l}{ Abstract PWE-167 Table 1} & IBS-QOL sexual subscale results \\
\hline & Placebo (ITT) & Linaclotide (ITT) & Change from baseline $\Delta$ & $P$-value (ITT) & Placebo (IS) & Linaclotide (IS) & Change from baseline $\Delta$ & $P$-value (IS) \\
\hline Overall (n) & 795 & 803 & 5.2 & $<0.0001^{*}$ & 249 & 273 & 7.2 & $0.0007^{*}$ \\
Baseline & $68.9(31.9)$ & $66.9(30.9)$ & & & $27.2(17.8)$ & $29.5(17.7)$ & & \\
Week 12 & $79.7(25.9)$ & $83.1(23.6)$ & & $57.8(29.9)$ & $67.9(28.1)$ & & \\
Females (n) & 706 & 733 & 5.2 & $<0.0001^{*}$ & 228 & 256 & 6.7 & $0.0016^{*}$ \\
Baseline & $68.0(32.3)$ & $66.1(31.1)$ & & & $26.6(17.8)$ & $29.5(17.8)$ & & \\
Week 12 & $79.8(25.8)$ & $83.2(23.4)$ & & $58.5(30.2)$ & $68.6(27.7)$ & & \\
Males (n) & 89 & 70 & 4.2 & $0.3129^{*}$ & 21 & 17 & 10.2 & $0.2389^{*}$ \\
Baseline & $76.3(28.1)$ & $74.5(28.7)$ & & $32.7(16.5)$ & $30.1(17.7)$ & & \\
Week 12 & $78.9(26.7)$ & $81.5(26.0)$ & & & $50.0(25.7)$ & $57.8(33.2)$ & & \\
\hline
\end{tabular}

Data are mean (SD)

${ }^{*} P$-values based on change-from-baseline treatment difference for linaclotide vs placebo (ANCOVA) 
Introduction Small Bowel Bacterial Overgrowth (SBBO) has recently been proposed to be prevalent in patients with diarrhoea predominant Irritable Bowel Syndrome (IBS-D). However prevalence figures in studies have varied widely dependant on the diagnostic test used, with low prevalence rates of $4 \%$ using jejunal aspirate and culture, to between $38-84 \%$ using hydrogen breath tests.

This study used the Glucose Hydrogen and Methane Breath Test (GHBT) to determine if there was a relationship between patients with IBS-D symptoms and SBBO. Concurrently any clinical features or baseline laboratory investigations indicative of a high likelihood of SBBO was investigated.

Methods A retrospective analysis of patient hospital records for patients referred to a tertiary GI Physiology Department at Sheffield Teaching Hospitals (STH) between January 1988-2013 for a routine GHBT was conducted. Data was split into two groups. Group 1 included all patients demographics referred for a GHBT (1998-2010) to investigate characteristics predictive of SBBO. Group 2 included patients who fulfilled ROME III criteria for IBS-D who underwent a GHBT (2010-2012). A positive result for SBBO was defined as a rise in hydrogen or methane levels of $\geq 10 \mathrm{ppm}$ over baseline levels.

Results In group 1786 patients were identified (276 male, mean age 54). Overall 175/786 (22.3\%) tests were positive. Laboratory investigations and patient characteristics predictive of a positive result were low vitamin $\mathrm{B}_{12}(\mathrm{p}<0.001)$, low albumin $<30 \mathrm{~g} / \mathrm{dL}$ ( $\mathrm{p}<0.001$ ), concurrent use of a proton pump inhibitor (PPI) ( $\mathrm{p}=0.002)$, previous Bilroth II gastroenterostomy ( $\mathrm{p}$ $<0.001$ ), previous vagotomy ( $\mathrm{p}<0.001$ ), right hemi-colectomy $(\mathrm{p}=0.003)$, coeliac disease $(\mathrm{p}<0.001)$, and small bowel Crohn's disease $(p=0.04)$ and age over 65 years $(p<0.001)$. Symptoms predictive of a positive GHBT included diarrhoea ( $p$ $=0.03)$ and weight loss $(\mathrm{p}<0.01)$.

In group 2 135/834 patients fulfilled ROME III criteria for IBS-D (42 male, mean age 43 years). Overall 26/135 (19.3\%) tests were positive. A significant correlation was found between patients with IBS-D symptoms and SBBO $(\mathrm{p}=0.01)$. Characteristics predictive of SBBO in IBS-D patients were previous small bowel surgery $(p=0.04)$ and blind loop syndrome $(p=0.04)$. Conclusion This study has further highlighted the proposed relationship of IBS-D symptoms and an increased prevalence of SBBO. In IBS-D patients factors predictive of SBBO were previous small bowel surgery and blind loop syndrome. For the sub-cohort of patients attending for a GHBT factors predictive of SBBO were patient age ( $\geq 65$ years), diarrhoea, weight loss, use of a PPI, previous Bilroth II gastroenterostomy, previous vagotomy, right hemi-colectomy, coeliac disease, small bowel Crohn's disease, low Vitamin $\mathrm{B}_{12}$ and low albumin.

Disclosure of Interest None Declared.

\section{PWE-169 PERCUTANEOUS TIBIAL NERVE STIMULATION HAS SUSTAINED BENEFIT AT 1 YEAR IN PATIENTS WITH FAECAL INCONTINENCE}

JB Cowley*, P Waudby, HL O'Grady, G Duthie. Academic Surgical Unit, Hull and East Yorkshire NHS Trust, Hull, UK

\subsection{6/gutjnl-2014-307263.429}

Introduction Faecal incontinence affects up to $18 \%$ of the adult population ${ }^{1}$ with obstetric trauma being the most common risk factor. ${ }^{2,3}$ Multiple techniques are used in its management with neuromodulation becoming increasingly popular. SNS is a safe and effective treatment for FI but has associated morbidity ${ }^{4}$ and costs. ${ }^{5}$ PTNS is an alternative that evolved from the treatment of urinary incontinence, ${ }^{6}$ involving stimulation of the tibial nerve. We aimed to assess functional outcome in patients treated with PTNS initially, post treatment and in those that have completed follow up at 1 year.

Methods All patients undergoing neuromopdulation with PTNS in our institution were included. Treatment regimens of $30 \mathrm{~min}$ PTNS for 12 weeks were undertaken. Patients were assessed with pre, post treatment and in those that qualify at 1 year with validated questionnaires. The questionnaires included the CCFIS and Rockwood FIQOL score. Data was analysed with SPSS using the Wilcoxon signed rank test with significance at $\mathrm{p}<0.05$.

Results 40 patients underwent PTNS, 36 female with median age 60 years (range 34-85). 30 were successful with a trial of PTNS, 9 failing and one lost to follow up. Of successful patients a further 4 were lost to follow up at a year. CCFIS scores were significantly improved in the post treatment group $(\mathrm{n}=38)$ with $\mathrm{z}=-3.75, \mathrm{p}<0.05 \mathrm{r}=-0.43$ and at 1 year $(\mathrm{n}=9) \mathrm{z}=-0.26$, $\mathrm{p}<0.05, \mathrm{r}=-0.63$. Comparison of the individual components of the FIQOL scores demonstrated significant improvement ( $\mathrm{p}$ $<0.05$ ) in lifestyle, coping, depression and embarrassment scores post treatment and at 1 year all other than lifestyle continued to show significance.

Conclusion PTNS shows significant benefit in CCFIS scores and FIQOL scores post treatment and at 1 year. Whilst patient numbers at 1 year are small this treatment is in its infancy and further long term studies will be needed to confirm benefit over time.

\section{REFERENCES}

1 Whitehead WE, Borrud L, Goode PS, et al. Fecal incontinence in US adults: epidemiology and risk factors. Gastroenterology 2009:137:512-517

2 Madoff RD, Williams JG, Caushaj PF. Fecal incontinence. N Engl J Med. 1992;326:1002-1007

3 Zutshi M, Tracey TH, Bast J, Halverson A, Na J. Ten-year outcomeafter anal sphincter repair for fecal incontinence. Dis Colon Rectum 2009:52:1089-1094

4 Dudding TC, Meng Lee E, Faiz O, Pares D, Vaizey CJ, McGuire A, et al. Economic evaluation of sacral nerve stimulation for faecal incontinence. Br J Surg 2008:95: 1155-1163

5 Sprange K, Clift M, Burke M, Whitehead SR, Hutton J. Evidence Review: Sacra Nerve Stimulation for Faecal Incontinence. Healthcare Innovation and Technology Evaluation Centre (HITEC): Derby, 2009

6 McGuire EJ, Zhang SC, Horwinski ER, Lytton B. Treatment of motor and sensory detrusor instability by electrical stimulation. J Urol 1983:129: 78-79

Disclosure of Interest None Declared.

\section{PWE-170 AN AUDIT OF CLINICAL RESPONSE IN PATIENTS WITH IBS TREATED WITH THE LOW FODMAP DIET AT ST MARY'S HOSPITAL}

V Mcgeoch, V Blackwell, L Wigham, JM Hoare*. Gastroenterology, Imperial College London, London, UK

\subsection{6/gutjn--2014-307263.430}

Introduction The low FODMAP diet is a diet used in patients with Irritable Bowel Syndrome. The diet is based on evidence that fermentable oligosaccharides, disaccharides, monosaccharides and polyols (FODMAPs) contribute to symptoms many people experience in Irritable Bowel Syndrome (IBS), including: bloating, flatulence and diarrhoea. ${ }^{1}$ This may be due to their fermentation by bacteria and osmotic effects on the bowel. ${ }^{2}$ The low FODMAP diet aims to reduce these carbohydrates and so reduce symptoms.

Methods The study included all patients treated with the low FODMAP diet at St Marys Hospital between November 2009 